\title{
Impact of bacterial infections on airway
} diseases

\author{
G.B. Toews
}

ABSTRACT: Bacterial infections play an important role as aetiologic agents in acute exacerbations of chronic obstructive pulmonary disease (COPD). Modern investigational tools, including bronchoscopy, microbial molecular epidemiology and measurement of specific immunity have established that bacteria cause up to $50 \%$ of acute exacerbations in COPD.

Acute exacerbations have enormous economic costs and contribute to morbidity, mortality and impairment in health related quality of life. Chronic bacterial persistence in the lower airways and lower respiratory tract in patients with COPD is not innocuous. It is likely to contribute to persistent airway inflammation and might contribute to acute airway exacerbations or progression of airway obstruction. Further investigation is required in these fertile areas of investigation.

Bacteria also play a role in asthma exacerbations, but their role is less well defined than with patients with COPD. Mycoplasma pneumoniae may be associated with asthma chronicity. Chronic airway infection models document that $M$. pneumoniae plays a role in airway remodelling, including angiogenesis, vascular remodelling and airway wall thickening.

Recent studies have identified patients with asthma as an at-risk group for invasive pneumococcal disease. The feasibility and cost effectiveness of a pneumococcal vaccination strategy among persons with asthma deserves careful, immediate attention.

KEYWORDS: Airways disease, asthma, bacterial infections, chronic obstructive pulmonary disease, pneumonia, vaccination

\section{COPD}

Chronic obstructive pulmonary disease (COPD) is the fourth leading cause of chronic morbidity and mortality in the USA and is currently the fourth leading cause of death in the world [1-3]. While mortality related to other leading causes of death (cardiac disease and malignancy) has declined substantially over the last decade, the mortality of COPD has been increasing worldwide [3].

Potential roles of bacterial infection in COPD The contributions of bacterial infection to the aetiology, pathogenesis and clinical course of COPD have been a source of controversy for several decades. Bacterial infection has been assigned a pre-eminent role in the pathogenesis of COPD; bacterial infections have also been dismissed as a mere epi-phenomenon [4-7].

Bacterial infection might contribute to the pathogenesis and clinical course of COPD in three ways: 1) lower respiratory tract infection during childhood might impair lung growth; 2) bacteria could account for a substantial portion of acute exacerbations of chronic bronchitis, a cause of considerable morbidity and mortality; 3) chronic colonisation of the lower respiratory tract or persistence in respiratory tissues could induce a chronic inflammatory response and thus contribute to the pathogenesis of disease.

\section{Childhood lower respiratory tract infections}

Adults who experience childhood lower respiratory tract infection consistently show a lower forced expiratory volume in one second (FEV1) and often lower forced vital capacity (FVC) when compared with others in the cohort who did not experience a childhood infection [8-10]. The extent of decrease in FEV1 is unlikely to cause symptomatic pulmonary disease, but could make the individual susceptible to the effects of additional injurious agents, such as tobacco smoke or exposure to airborne pollutants. While the association between childhood lower respiratory tract infection and impaired lung function in adulthood is well established, it is uncertain that this association reflects a cause-effect relationship. Two possibilities exist. Childhood infection could damage a vulnerable lung undergoing rapid postnatal growth and development. Alternatively, genetic factors may predispose
CORRESPONDENCE

G.B. Toews

Division of Pulmonary \& Critical Care Medicine

The University of Michigan Health System

1150 W. Medical Center Drive /

6301 MSRB III

Ann Arbor

Michigan 48109-0642

USA

Fax: 17347642655

E-mail: gtoews@umich.edu 
certain individuals to lower respiratory tract infections as well as a lower FEV1 in childhood. In one instance, infection antedates impaired lung growth while in the other instance impaired growth antedates the respiratory infection.

\section{Bacterial pathogens as aetiologic agents in acute exacerbations of COPD}

There is considerable debate regarding the definition of an acute exacerbation of COPD. An acute exacerbation remains a subjective, symptom based, patient reported clinical event. Acute exacerbations are usually defined as a minor increase (or new onset) of two or a major increase (or new onset) of one of the following respiratory symptoms: cough, dyspnoea, sputum production, sputum tenacity, or sputum purulence. The altered symptoms must be present for at least $24 \mathrm{~h}$ and must be of greater intensity than normal day-to-day variability.

Bacteria, viruses and atypical pathogens are implicated as aetiologic agents of up to $80 \%$ of acute exacerbations [11]. While considerable controversy exists regarding the role of bacteria in acute exacerbations, recent studies that have utilised modern investigational tools including bronchoscopy, microbial molecular epidemiology and measurement of specific immunity, have established that bacteria cause up to $50 \%$ of acute exacerbations [12]. Significant bacterial infection was noted in $\sim 50 \%$ of patients with acute exacerbations who had bronchoscopic sampling of lower airway secretions [13-15]. Lower concentrations of bacteria were present in the lower airways of $25 \%$ of patients who had stable COPD. Bronchial mucosal biopsies obtained from patients intubated for acute exacerbations revealed intracellular nontypable Haemophilus influenzae (NTHI) in $87 \%$ of patients with exacerbations, compared with $33 \%$ of patients who had stable COPD. Intracellular NTHI were not noted in any healthy controls [16]. The increased rate of isolation of pathogenic bacteria from the lower respiratory tract during acute exacerbations compared with stable COPD substantially supports the pathogenic role of bacterial in acute exacerbations.

Early studies found no difference in the isolation rate of bacterial pathogens during exacerbations and stable COPD [17, 18]. These cohort studies did not differentiate among strains of pathogens isolated from sputum over time. A recent longitudinal cohort study demonstrated that the acquisition of a novel bacterial strain was associated with a greater than twofold increase in risk for an exacerbation. This increased risk for exacerbation was seen with acquisition of novel strains of NTHI, Moraxella catarrhalis and Streptococcus pneumoniae, but not with strains of Pseudomonas aeruginosa. This study provides support for bacteria as aetiologic agents in a substantial portion of exacerbations. Additionally, this study suggests that infection with a bacterium that is new to the host is a major mechanism of recurrent acute exacerbations in COPD [19].

Further support for the role of novel bacterial strains in the aetiology of acute exacerbations of COPD comes from studies of specific immune responses following exacerbations. An immune response to the infecting NTHI strain was demonstrated after $61 \%$ of exacerbations associated with strains that were new to the patient; an immune response to the infecting NTHI strain was noted in only $21 \%$ of exacerbations associated with a pre-existing strain. New bactericidal antibodies that developed after an exacerbation were highly strain specific, showing bactericidal activity for only $12 \%$ of heterologous strains isolated from other patients. Development of a strainspecific immune response provides further support for a causal role of bacteria during acute exacerbations [20].

Considerable confusion exists regarding the importance and incidence of Mycoplasma pneumoniae, Chlamydophila (formerly Chlamydia) pneumoniae and Legionella species infections in acute exacerbations of COPD. This confusion is related both to the definition of exacerbations used in the studies as well as to methods used to determine the presence of infection with one of these microbes. In studies with rigorous methodology to exclude pneumonia and rigorous diagnostic criteria, including a strict four-fold increase in titre or a positive culture, M. pneumoniae or Legionella species are rare in acute exacerbations and the incidence of $C$. pneumoniae is $\sim 5 \%$ $[21,22]$.

The impact of repeated exacerbations on pulmonary function is a matter of intense debate $[7,23]$. In a longitudinal study of 101 patients, acute exacerbations of COPD significantly impaired pulmonary functions and increased symptoms with a mean time for recovery of 6 days and 7 days, respectively [24]. However, even by 35 days recovery was incomplete in $25 \%$ (by pulmonary function) and $14 \%$ (by symptoms) of patients. Thus, even single episodes trigger prolonged disability in a subset of patients. More ominous, though controversial, is mounting evidence that more frequent acute exacerbations of COPD accelerate physiological decline. Early cohort studies that included nonsmokers concluded that chronic bronchitis is unrelated to the development of chronic airflow obstruction [25-27], but more recent data imply that repeated acute exacerbations of COPD are indeed associated with increased decrements in airflow $[28,29]$. The number of respiratory infections influences the rate of decline in FEV1 in those who continued smoking in the Lung Health Study. Smokers suffered an additional $7 \mathrm{~mL}$ decline in FEV1 for every additional exacerbation [29]. The negative impact of exacerbations on lung function has also been demonstrated in a longitudinal study of patients with emphysema due to $\alpha_{1^{-}}$ antitrypsin deficiency. Significant correlations between exacerbation frequency and rate of decline in FEV1 were noted [30]. Thus, the influence of infections on the progression of COPD may be more evident in patients with added risk factors for rapid progression of disease, such as active smokers or patients with $\alpha_{1}$-antitrypsin deficiency.

The importance of acute exacerbations of COPD are also shown by their economic costs, estimated at $\$ 1.2$ billion in patients aged $>65 \mathrm{yrs}$ and $\$ 419$ million in patients aged $<65$ yrs. This burden is greatest in those requiring hospitalisation, who account for the bulk of costs of acute exacerbations $[31,32]$. Emergency room visits for acute exacerbations alone predict significant impairment in health-related quality of life, whereas episodes severe enough to warrant hospitalisation result in marked impairment in the next 6 months [33]. Hospitalisations for acute exacerbations of COPD are associated with a high risk of readmission in both the USA and elsewhere [34-37]. Thus, acute exacerbations of COPD result in major symptomatic, physiological and economic burden. 


\section{Chronic persistence of bacteria in respiratory tissues}

NTHI are present in up to three-quarters of healthy adults. Virtually all patients with chronic bronchitis are colonised with NTHI if serial cultures are performed. Colonisation with NTHI is a dynamic process; new strains are periodically acquired and replace old strains [38]. The adherence of NTHI to the human respiratory tract is a complex interaction of bacterial adhesins and host molecules. NTHI most likely initially encounters mucus in the respiratory tract. Mucus is a complex mixture of debris, cells and secreted molecules including mucins. Mucins bind NTHI and may influence bacterial adhesion to the epithelium. Binding of mucin is mediated by outer membrane proteins $[39,40]$. An understanding of the molecular interactions of mucin with NTHI might allow development of strategies to prevent colonisation and infection.

Multiple adhesins expressed by NTHI are involved in adherence to the respiratory epithelium [41]. NTHI express pili that mediate adherence to mucosal cells [42]. Pili are hairlike projections with a distal tip adhesin. Nonpiliated strains of NTHI are also capable of adhering to human epithelial cells, suggesting the presence of nonpilus adhesins [43]. While numerous adhesins have been identified and the ability of the bacterium to modulate expression of adhesins has been defined, the conditions under which specific adhesins are expressed in patients are unclear.

NTHI's niche in the human respiratory tract is not limited to the surface of epithelial cells. A small percentage of adherent NTHI enter epithelial cells via an entry process that involves actin filaments and microtubules [44]. Bacteria may penetrate epithelial cells by paracytosis or passage between cells. Bacteria pass through confluent layers of epithelial cells without affecting the permeability or viability of the cells [45]. Intracellular NTHI are protected from the bactericidal activity of antibiotics and antibody-mediated bactericidal activity [46]. It is believed that NTHI preferentially, or perhaps exclusively, enter nonciliated cells within the population [47]. In vivo studies also confirm NTHI penetrate the mucosal surface. NTHI are present in macrophage-like cells in the adenoids of children [48], and NTHI are diffusely present in the epithelium, the submucosal of the bronchi, the bronchioles, the interstitium, and the alveolar epithelium in lung explants from patients undergoing lung transplantation [49]. Finally, NTHI may persist in the respiratory tract in biofilms. $H$. influenzae is known to form biofilms in vitro and in vivo [50]. Bacteria present in the airways in the form of biofilms may yield negative cultures because routine cultures are less sensitive in detecting bacteria in biofilms. H. influenzae is known to grow as a biofilm and planktonically under different conditions. NTHI may shift from planktonic growth to biofilms as a strategy of persistence.

Chronic bacterial persistence in the lower airways could perpetuate inflammation and contribute to progression of disease [7]. Cell-free supernatants of NTHI inhibit ciliary beat frequency [51] and induce ciliary dyskinesis and ciliostasis. NTHI stimulates mucin secretion [52] and causes airway epithelial injury in vitro [53]. Finally, the presence of bacteria in the lower airways induces the production of inflammatory mediators by the airway epithelium. Different species elicit different degrees of inflammatory reaction. The most intense inflammation is generated by $P$. aeruginosa, followed by $H$. influenzae; $M$. catarrhalis provokes significantly milder inflammatory response $[11,54]$. NTHI and lipooligosaccharide from NTHI increase interlukin (IL)-6, tumour necrosis factor- $\alpha$ and IL-8 production [55].

It is increasingly apparent that chronic persistence of bacteria in the lower airways of patients with COPD is not innocuous. NTHI has the ability to disrupt ciliary motility, induce mucus hypersecretion and damage airway epithelium. NTHI persistence stimulates airway epithelial cells to produce proinflammatory cytokines, especially those that promote neutrophil chemotaxis. The relation of persistent airway inflammation to the symptoms of acute exacerbations and to progression of airway obstruction is a fertile area of investigation (fig. 1).

\section{ASTHMA}

The incidence of asthma has increased worldwide over the past decade. Factors that influence the development and severity of asthma include environmental exposures, genetic predisposition, environment/gene interactions, atopy, diet, socio-economic status and infection. Certain bacteria are contributors to some asthma exacerbations, and bacteria may play a complex role in the development of asthma [56].

\section{Exacerbations of asthma}

The precise incidence of bacterial infection in asthma exacerbations has not been determined. In most instances, studies have not demonstrated cause and effect relationships. Several pathophysiological mechanisms may account for bacterial involvement in asthma exacerbations. Sinusitis is an important trigger of asthma exacerbations. Sinusitis is extremely common in asthmatic patients, with a prevalence ranging from $53-75 \%$. S. pneumoniae and $H$. influenzae account for $76 \%$ of positive cultures in sinusitis [57]. M. catarrhalis is more commonly isolated from the upper airway of asthmatics than from the upper airway of normal patients. $M$. catarrhalis was present in one-third of normal patients. Altogether, $70 \%$ of well asthmatics and $75 \%$ of asthmatics experiencing exacerbations had positive cultures for $M$. catarrhalis on pharyngeal swabs. No causal relationships were identified in this study [58]. A recent serologically based prospective study demonstrated a link between atypical infectious organisms and asthma exacerbations [59]. One hundred patients hospitalised with exacerbations of asthma were compared with hospitalised surgical patients with no history of lung disease or history of a upper respiratory tract infection in the month before admission. $M$. pneumoniae was identified more than any other pathogen in the asthmatic group (18 M. pneumoniae, 11 influenza A, eight $C$. pneumoniae, six adenovirus, five influenza B, five Legionella species and three S. pneumoniae) and in the control group (three $M$. pneumoniae). Interestingly, $M$. pneumoniae was the sole infectious agent in only eight of the 18 patients in which $M$. pneumoniae was identified, illustrating the difficulty in ascertaining a cause-effect relationship of $M$. pneumoniae as the cause of the hospitalisation.

Several studies have evaluated the role of M. pneumoniae and $C$. pneumoniae in acute wheezing in children [60, 61]. $M$. pneumoniae was detected in $20 \%$ and C. pneumoniae in $5-15 \%$ 


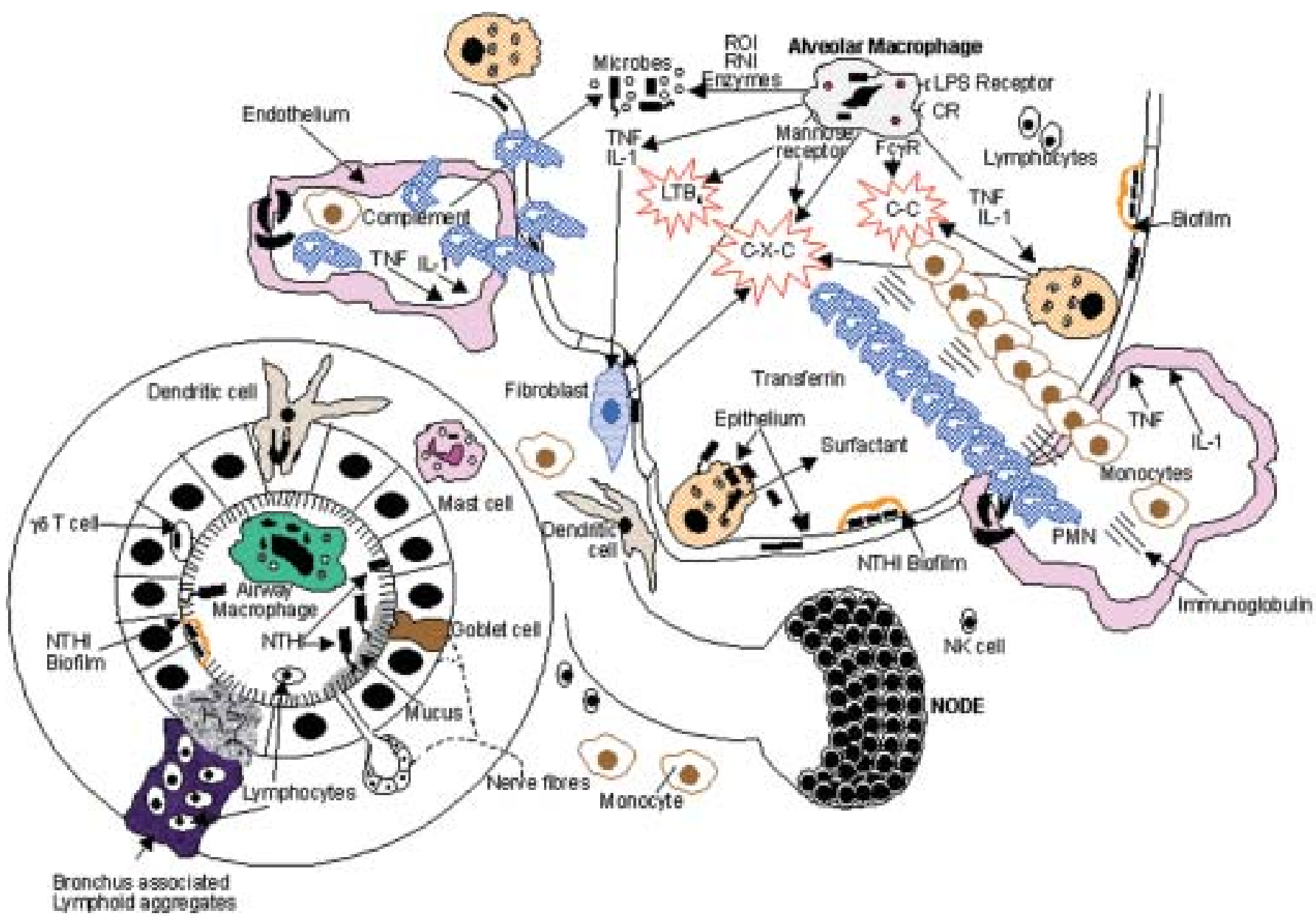

FIGURE 1. Host defences of conducting airways and alveoli. Conducting airways are lined by ciliated epithelium, which moves mucus generated by bronchiolar glands and goblet cells cephalad. Nontypable Haemophilus influenzae binds to mucus via pili and to respiratory epithelia via pili and nonpilus adhesins. Bacteria also penetrate epithelial cells. Bacteria may persist in the respiratory tract in biofilms. Airway macrophages ingest and kill small inocula of most inspired and airborne bacteria. Ingestion of microbes stimulates alveolar macrophages to produce tumour necrosis factor- $\alpha$ (TNF- $\alpha$ ), C-C and C-X-C chemokines and leukotriene B4 (LTB 4 ), which mediate inflammatory responses in the airway and lower respiratory tract. IL-1: interleukin 1; LPS: lipopolysaccharide; NK: natural killer; PMN: polymorphonucleates. Modified with permission from: Toews GB. Pulmonary Clearance of Infectious Agents. In: Fishman's Pulmonary Diseases and Disorders, 3rd edn, vol 2. Eds: Fishman AF, Elias JA, Fishman JA, et al. McGraw Hill, New York, 1997, p. 1893.

of children with wheezing compared with $7.5 \%$ and $2.5 \%$, respectively in healthy control children. Acute $M$. pneumoniae infection was confirmed in $50 \%$ and C. pneumoniae infection in $8.3 \%$ of patients experiencing their first wheezing episode. Further studies are needed to confirm the association between bacterial infection and asthma exacerbation and to determine the prevalence of such infection in patients with acute exacerbations of asthma.

\section{Role of bacteria in chronic asthma}

M. pneumoniae and C. pneumoniae may be associated with asthma chronicity [62]. The role of M. pneumoniae and C. pneumoniae infections with chronic asthma has been evaluated using PCR, culture and serology to detect M. pneumoniae, C. pneumoniae and viruses. Altogether, $56 \%$ of asthmatic patients had a positive PCR for M. pneumoniae $(\mathrm{n}=25)$ or C. pneumoniae $(n=7)$. Positive results for PCR were found in broncholaveolar lavage (BAL) fluid or biopsy samples. Only one of 11 control subjects had a positive PCR for M. pneumoniae. Cultures for these organisms were negative in all patients. A significantly greater number of tissue mast cells were noted in the group of patients who were PCR positive.

Asthmatic patients infected with M. pneumoniae or C. pneumoniae may benefit from prolonged treatment with clarithromycin [63]. Treatment with clarithromycin resulted in significant improvement in FEV1, and FVC; the greatest improvement was noted when PCR-positive patients received clarithromycin. While the studies to evaluate the effect of clarithromycin in patients with asthma are randomised, double-blind and placebo controlled, the number of patients enrolled in these studies is small. Further study is needed to assess if the presence of $M$. pneumoniae and C. pneumoniae is an epiphenomenon or related to the pathogenesis of asthma. The effects of clarithromycin could be secondary to its antimicrobial effects, its anti-inflammatory effects or to a combination of these two therapeutic effects. 


\section{Animal models of Mycoplasma pneumoniae infection}

Murine models of acute and chronic M. pneumoniae respiratory tract infection show many similarities to human disease and allow a complementary investigation of the complex interactions of Mycoplasma infection and the host [64-67]. $M$. pneumoniae infection in chronic mouse models can be detected up to $1.5 \mathrm{yrs}$ after resolution of the pneumonia [64]. Murine lungs exhibit inflammatory changes, alteration in lung histology, antibody production, cytokine release into the BAL fluid and persistent airflow resistance [64]. Bronchial hyperresponsiveness and airway neutrophilia have also been demonstrated during chronic M. pneumoniae infection [66]. Chronic airway infection models have also been utilised to characterise the mechanisms underlying angiogenesis, vascular remodelling and airway wall thickening [67]. Such remodelling can be induced in concert with inflammatory responses to Mycoplasma infection. Vascular leak is promoted by vascular endothelial growth factor and is opposed by angiopoietin 1 . Both molecules are stimulated by $M$. pneumoniae infection. The role of $M$. pneumoniae infection in the airway remodelling noted in chronic asthmatics deserves further detailed study.

\section{AIRWAYS DISEASE AS A RISK FACTOR FOR INVASIVE PNEUMOCOCCAL DISEASE}

Streptococcus pneumoniae is a cause of substantial morbidity and mortality in the USA, particularly among patients with high risk medical illness [68]. Pneumococcal vaccination has been shown to prevent invasive disease from this ubiquitous pathogen, particularly in high risk groups [68, 69]. While chronic obstructive pulmonary diseases (emphysema and chronic bronchitis) have long been included as an at-risk group for whom pneumococcal vaccination is recommended, guidelines for pneumococcal vaccinations specifically excluded subjects with asthma and the guidelines for the management of asthma do not include pneumococcal vaccination as a strategy to prevent infectious complications. A recent nested, case-controlled study documented that asthma is an independent risk factor for invasive pneumococcal disease [70]. Subjects with asthma who had a history of one or more hospitalisations or visits to an emergency department for asthma, or who were given a prescription for a course of corticosteroids as rescue therapy, or a long-term course of oral corticosteroids (120 days or more) or prescriptions for three or more $\beta$-agonists medications during the year before the index date, were classified as having high-risk asthma. All other subjects with asthma were classified as having low-risk asthma. The annual incidence of invasive pneumococcal disease was 4.2 episodes per 10,000 subjects with high-risk asthma, and 2.3 episodes per 10,000 subjects with low-risk asthma. Subjects aged $\geqslant 65 \mathrm{yrs}$ experience 8.3 episodes per 10,000 subjects as a comparison [71]. This recent study provides strong evidence for the addition of asthma to the list of conditions that increase the risk of invasive pneumococcal disease. The feasibility and cost effectiveness of a pneumococcal vaccination among persons with asthma deserves careful, immediate study.

\section{REFERENCES}

1 American Thoracic Society. Standards for the diagnosis and care of patients with chronic obstructive pulmonary disease. Am J Respir Crit Care Med 1995; 152: S77-S121.
2 Pauwels RA, Buist AS, Calverley PM, Jenkins CR, Hurd SS. Global strategy for the diagnosis, management, and prevention of chronic obstructive pulmonary disease. NHLBI/WHO Global Initiative for Chronic Obstructive Lung Disease (GOLD) Workshop summary. Am J Respir Crit Care Med 2001; 163: 1256-1276.

3 World Health Organisation. 2000. World Health Report.

4 Leeder SR. Role of infection in the cause and course of chronic bronchitis and emphysema. J Infect Dis 1975; 131: 731-742.

5 Tager I, Speizer FE. Role of infection in chronic bronchitis. N Engl J Med 1975; 292: 563-571.

6 MRC. Definition and classification of chronic bronchitis for clinical and epidemiological purposes. A report to the Medical Research Council by their Committee on the Aetiology of Chronic Bronchitis. Lancet 1965; 1: 775-779.

7 Murphy TF, Sethi S. Bacterial infection in chronic obstructive pulmonary disease. Am Rev Respir Dis 1992; 146: 1067-1083.

8 Johnston ID, Strachan DP, Anderson HR. Effect of pneumonia and whooping cough in childhood on adult lung function. N Engl J Med 1998; 338: 581-587.

9 Shaheen SO, Barker DJ, Shiell AW, Crocker FJ, Wield GA, Holgate ST. The relationship between pneumonia in early childhood and impaired lung function in late adult life. Am J Respir Crit Care Med 1994; 149: 616-619.

10 Shaheen SO, Sterne JA, Tucker JS, Florey CD. Birth weight, childhood lower respiratory tract infection, and adult lung function. Thorax 1998; 53: 549-553.

11 Sethi S. Infectious etiology of acute exacerbations of chronic bronchitis. Chest 2000; 117: 5 Suppl. 2, 380S-385S.

12 Sethi S, Murphy TF. Bacterial infection in chronic obstructive pulmonary disease in 2000: a state-of-the-art review. Clin Microbiol Rev 2001; 14: 336-363.

13 Monso E, Ruiz J, Rosell A, et al. Bacterial infection in chronic obstructive pulmonary disease. A study of stable and exacerbated outpatients using the protected specimen brush. Am J Respir Crit Care Med 1995; 152: 1316-1320.

14 Fagon JY, Chastre J, Trouillet JL, et al. Characterization of distal bronchial microflora during acute exacerbation of chronic bronchitis. Use of the protected specimen brush technique in 54 mechanically ventilated patients. Am Rev Respir Dis 1990; 142: 1004-1008.

15 Soler N, Torres A, Ewig S, et al. Bronchial microbial patterns in severe exacerbations of chronic obstructive pulmonary disease (COPD) requiring mechanical ventilation. Am J Respir Crit Care Med 1998; 157: 1498-1505.

16 Bandi V, Apicella MA, Mason E, et al. Nontypeable Haemophilus influenzae in the lower respiratory tract of patients with chronic bronchitis. Am J Respir Crit Care Med 2001; 164: 2114-2119.

17 Gump DW, Phillips CA, Forsyth BR, McIntosh K, Lamborn KR, Stouch WH. Role of infection in chronic bronchitis. Am Rev Respir Dis 1976; 113: 465-474.

18 McHardy VU, Inglis JM, Calder MA, et al. A study of infective and other factors in exacerbations of chronic bronchitis. Br J Dis Chest 1980; 74: 228-238.

19 Sethi S, Evans N, Grant BJ, Murphy TF. New strains of bacteria and exacerbations of chronic obstructive pulmonary disease. N Engl J Med 2002; 347: 465-471. 
20 Sethi S, Wrona C, Grant BJ, Murphy TF. Strain-specific immune response to Haemophilus influenzae in chronic obstructive pulmonary disease. Am J Respir Crit Care Med 2004; 169: 448-453.

21 Beaty CD, Grayston JT, Wang SP, Kuo CC, Reto CS, Martin TR. Chlamydia pneumoniae, strain TWAR, infection in patients with chronic obstructive pulmonary disease. Am Rev Respir Dis 1991; 144: 1408-1410.

22 Blasi F, Legnani D, Lombardo VM, et al. Chlamydia pneumoniae infection in acute exacerbations of COPD. Eur Respir J 1993; 6: 19-22.

23 Wilson R. Bacteria, antibiotics and COPD. Eur Respir J 2001; 17: 995-1007.

24 Seemungal TA, Donaldson GC, Bhowmik A, Jeffries DJ, Wedzicha JA. Time course and recovery of exacerbations in patients with chronic obstructive pulmonary disease. Am J Respir Crit Care Med 2000; 161: 1608-1613.

25 Howard P. A long-term follow-up of respiratory symptoms and ventilatory function in a group of working men. Br J Ind Med 1970; 27: 326-333.

26 Bates DV. The fate of the chronic bronchitic: a report of the ten-year follow-up in the Canadian Department of Veteran's Affairs coordinated study of chronic bronchitis. The J. Burns Amberson Lecture of the American Thoracic Society. Am Rev Respir Dis 1973; 108: 1043-1065.

27 Fletcher C, Peto R, Tinker C, Speizer F. The natural history of chronic bronchitis and emphysema. New York: Oxford University Press, 1976: 272.

28 Seemungal $\mathrm{T}$, Harper-Owen $\mathrm{R}$, Bhowmik $\mathrm{A}$, et al. Respiratory viruses, symptoms, and inflammatory markers in acute exacerbations and stable chronic obstructive pulmonary disease. Am J Respir Crit Care Med 2001; 164: 1618-1623.

29 Kanner RE, Anthonisen NR, Connett JE. Lower respiratory illnesses promote $\mathrm{FEV}(1)$ decline in current smokers but not ex-smokers with mild chronic obstructive pulmonary disease: results from the lung health study. Am J Respir Crit Care Med 2001; 164: 358-364.

30 Dowson LJ, Guest PJ, Stockley RA. Longitudinal changes in physiological, radiological, and health status measurements in alpha(1)-antitrypsin deficiency and factors associated with decline. Am J Respir Crit Care Med 2001; 164: 1805-1809.

31 Saint S, Flaherty KR, Abrahamse P, Martinez FJ, Fendrick AM. Acute exacerbation of chronic bronchitis: disease-specific issues that influence the cost-effectiveness of antimicrobial therapy. Clin Ther 2001; 23: 499-512.

32 Niederman MS, McCombs JS, Unger AN, Kumar A, Popovian R. Treatment cost of acute exacerbations of chronic bronchitis. Clin Ther 1999; 21: 576-591.

33 Aaron SD, Vandemheen KL, Clinch JJ, et al. Measurement of short-term changes in dyspnea and disease-specific quality of life following an acute COPD exacerbation. Chest 2002; 121: 688-696.

34 Connors AF Jr, Dawson NV, Thomas C, et al. Outcomes following acute exacerbation of severe chronic obstructive lung disease. The SUPPORT investigators (Study to Understand Prognoses and Preferences for Outcomes and Risks of Treatments). Am J Respir Crit Care Med 1996; 154: 959-967.
35 Osman L, Godden D, Friend J, Legge J, Douglas J. Quality of life and hospital re-admission in patients wth chronic obstructive pulmonary disease. Thorax 1997; 52: 67-71.

36 Cotton MM, Bucknall CE, Dagg KD, et al. Early discharge for patients with exacerbations of chronic obstructive pulmonary disease: a randomized controlled trial. Thorax 2000; 55: 902-906.

37 Skwarska E, Cohen G, Skwarski KM, et al. Randomized controlled trial of supported discharge in patients with exacerbations of chronic obstructive pulmonary disease. Thorax 2000; 55: 907-912.

38 Samuelson A, Freijd A, Jonasson J, Lindberg AA. Turnover of nonencapsulated Haemophilus influenzae in the nasopharynges of otitis-prone children. J Clin Microbiol 1995; 33: 2027-2031.

39 Reddy MS, Bernstein JM, Murphy TF, Faden HS. Binding between outer membrane proteins of nontypeable Haemophilus influenzae and human nasopharyngeal mucin. Infect Immun 1996; 64: 1477-1479.

40 Reddy MS, Murphy TF, Faden HS, Bernstein JM. Middle ear mucin glycoprotein: purification and interaction with nontypable Haemophilus influenzae and Moraxella catarrhalis. Otolaryngol Head Neck Surg 1997; 116: 175-180.

41 St Geme JW 3rd. Insights into the mechanism of respiratory tract colonization by nontypable Haemophilus influenzae. Pediatr Infect Dis J 1997; 16: 931-935.

42 Gilsdorf JR, McCrea KW, Marrs CF. Role of pili in Haemophilus influenzae adherence and colonization. Infect Immun 1997; 65: 2997-3002.

43 Barenkamp SJ, Leininger E. Cloning, expression, and DNA sequence analysis of genes encoding nontypeable Haemophilus influenzae high-molecular-weight surfaceexposed proteins related to filamentous hemagglutinin of Bordetella pertussis. Infect Immun 1992; 60: 1302-1313.

44 St Gem JW 3rd, Falkow S. Haemophilus influenzae adheres to and enters cultured human epithelial cells. Infect Immun 1990; 58: 4036-4044.

45 van Schilfgaarde M, van Alphen L, Eijk P, Everts V, Dankert J. Paracytosis of Haemophilus influenzae through cell layers of NCI-H292 lung epithelial cells. Infect Immun 1995; 63: 4729-4737.

46 van Schilfgaarde M, Eijk P, Regelink A, et al. Haemophilus influenzae localized in epithelial cell layers is shielded from antibiotics and antibody-mediated bactericidal activity. Microb Pathog 1999; 26: 249-262.

47 Ketterer MR, Shao JQ, Hornick DB, Buscher B, Bandi VK, Apicella MA. Infection of primary human bronchial epithelial cells by Haemophilus influenzae: macropinocytosis as a mechanism of airway epithelial cell entry. Infect Immun 1999; 67: 4161-4170.

48 Forsgren J, Samuelson A, Ahlin A, Jonasson J, RynnelDagoo B, Lindberg A. Haemophilus influenzae resides and multiplies intracellularly in human adenoid tissue as demonstrated by in situ hybridization and bacterial viability assay. Infect Immun 1994; 62: 673-679.

49 Moller LV, Timens W, van der Bij W, et al. Haemophilus influenzae in lung explants of patients with end-stage pulmonary disease. Am J Respir Crit Care Med 1998; 157: 950-956. 
50 Murphy TF, Kirkham C. Biofilm formation by nontypeable Haemophilus influenzae: strain variability, outer membrane antigen expression and role of pili. BMC Microbiology 2002; 2: 7.

51 Wilson R, Roberts D, Cole P. Effect of bacterial products on human ciliary function in vitro. Thorax 1985; 40: 125-131.

52 Adler KB, Hendley DD, Davis GS. Bacteria associated with obstructive pulmonary disease elaborate extracellular products that stimulate mucin secretion by explants of guinea pig airways. Am J Pathol 1986; 125: 501-514.

53 Read RC, Wilson R, Rutman A, et al. Interaction of nontypable Haemophilus influenzae with human respiratory mucosa in vitro. I Infect Dis 1991; 163: 549-558.

54 Hill AT, Campbell EJ, Hill SL, Bayley DL, Stockley RA. Association between airway bacterial load and markers of airway inflammation in patients with stable chronic bronchitis. Am J Med 2000; 109: 288-295.

55 Khair OA, Davies RJ, Devalia JL. Bacterial-induced release of inflammatory mediators by bronchial epithelial cells. Eur Respir J 1996; 9: 1913-1922.

56 Bousquet J, Jeffery PK, Busse WW, Johnson M, Vignola AM. Asthma. From bronchoconstriction to airways inflammation and remodeling. Am J Respir Crit Care Med 2000; 161: 1720-1745.

57 Senior BA, Kennedy DW. Management of sinusitis in the asthmatic patient. Ann Allergy Asthma Immunol 1996; 77: 6-15.

58 Seddon PC, Sunderland D, O'Halloran SM, Hart CA, Heaf DP. Branhamella catarrhalis colonization in preschool asthmatics. Pediatr Pulmonol 1992; 13: 133-135.

59 Lieberman D, Printz S, Ben-Yaakov M, et al. Atypical pathogen infection in adults with acute exacerbation of bronchial asthma. Am J Respir Crit Care Med 2003; 167: 406-410.

60 Esposito S, Blasi F, Arosio C, et al. Importance of acute Mycoplasma pneumoniae and Chlamydia pneumoniae infections in children with wheezing. Eur Respir J 2000; 16: 1142-1146.

61 Biscardi S, Lorrot M, Marc E, et al. Mycoplasma pneumoniae and asthma in children. Clin Infect Dis 2004; 38: 1341-1346.
62 Martin RJ, Kraft M, Chu HW, Berns EA, Cassell GH. A link between chronic asthma and chronic infection. J Allergy Clin Immunol 2001; 107: 595-601.

63 Kraft M, Hamid Q, Cassell G, et al. Mycoplasma and chlamydia cause increased airway inflammation that is responsive to clarithromycin. Am J Respir Crit Care Med 1999; 159: A517.

64 Hardy RD, Jafri HS, Olsen K, et al. Elevated cytokine and chemokine levels and prolonged pulmonary airflow resistance in a murine Mycoplasma pneumoniae pneumonia model: a microbiologic, histologic, immunologic, and respiratory plethysmographic profile. Infect Immun 2001; 69: 3869-3876.

65 Hardy RD, Jafri HS, Olsen K, et al. Mycoplasma pneumoniae induces chronic respiratory infection, airway hyperreactivity, and pulmonary inflammation: a murine model of infection-associated chronic reactive airway disease. Infect Immun 2002; 70: 649-654.

66 Martin RJ, Chu HW, Honour JM, Harbeck RJ. Airway inflammation and bronchial hyperresponsiveness after Mycoplasma pneumoniae infection in a murine model. Am J Respir Cell Mol Biol 2001; 24: 577-582.

67 McDonald DM. Angiogenesis and remodeling of airway vasculature in chronic inflammation. Am J Respir Crit Care Med 2001; 164: S39-S45.

68 Prevention of pneumococcal disease: recommendations of the Advisory Committee on Immunization Practices (ACIP). MMWR Recomm Rep 1997; 46: 1-24.

69 Preventing pneumococcal disease among infants and young children. Recommendations of the Advisory Committee on Immunization Practices (ACIP). MMWR Recomm Rep 2000; 49: 1-35.

70 Talbot TR, Hartert TV, Mitchel E, et al. Asthma as a risk factor for invasive pneumococcal disease. $N$ Engl J Med 2005; 352: 2082-2090.

71 Plouffe JF, Breiman RF, Facklam RR. Bacteremia with Streptococcus pneumoniae. Implications for therapy and prevention. Franklin County Pneumonia Study Group. JAMA 1996; 275: 194-198. 